\title{
Factors that influence emergency department visits for asthma
}

\author{
SC Tough PhD ${ }^{1}$, PA Hessel PhD ${ }^{1}$, FHY Green $M^{2}$, \\ I Mitchell MB ChB DCH FRCP(Edin\&Glas) FCCP FRCPC ${ }^{3}$, S Rose PhD ${ }^{2}, \mathrm{H}_{\text {Aronson MD }}^{4}$, \\ JC Butt MD FRCPath ${ }^{5}$ for the Prairie Provinces Asthma Study Group* \\ ${ }^{1}$ Department of Public Health Sciences, University of Alberta, Edmonton, Alberta; \\ ${ }^{2}$ Department of Pathology, University of Calgary; ${ }^{3}$ Department of Pediatrics, \\ Alberta Children's Hospital, Calgary, Alberta; ${ }^{4}$ Lethbridge Regional Hospital, \\ Lethbridge, Alberta; ${ }^{5}$ Chief Medical Examsiner's Office, Halifax, Nova Scotia
}

\begin{abstract}
SC Tough, PA Hessel, FHY Green, et al. Factors that influence emergency department visits for asthma. Can Respir J 1999;6(5):429-435.
\end{abstract}

BACKGROUND: Asthma can usually be controlled through allergen avoidance and/or appropriate medication. An emergency department visit for an acute exacerbation of asthma often represents a breakdown in asthma management. Emergency department treatment results in significant health care expenditures and reflects a compromised quality of life. OBJECTIVES: To identify risk factors associated with an emergency department visit for asthma.

METHODS: This case-control study compared 299 people (76\% of 390 cases contacted) who attended one of two emergency departments in Alberta in 1992 and 1993 for an acute exacerbation of asthma (cases) with 212 unmatched community controls with asthma who were located by random digit dialing. Cases and controls were asked to complete a mailed questionnaire to obtain data regarding severity, visits to doc- tors and emergency departments, medication use, allergies and other triggers, and smoking history. Data analysis included bivariate analysis of risk factors and multivariate model development using logistic regression.

RESULTS: The response rate was similar between cases and controls. Cases were younger than controls (odds ratio [OR] 2.16, 95\% CI 1.34 to 3.48) and more often reported their asthma to be severe (OR 4.25, 95\% CI 2.24 to 8.06), and had experienced nocturnal symptoms (stratified OR range 1.36 to 6.82 ). Cases used more health care services in the previous year, had been admitted to hospital at some time for asthma (OR $1.62,95 \%$ CI 1.10 to 2.38 ) and used more medication than controls.

CONCLUSIONS: Physicians and other health care workers should be sensitive to the risk factors and target interventions to high risk individuals.

Key Words: Asthma; Case-control study; Nocturnal asthma; Symptoms; Trigger factors

Pour le résumé, voir page suivante

*The Prairie Provinces Asthma Study Group: Thambirajah Balachandra, Winnipeg, Manitoba; Drummond Bowden Winnipeg, Manitoba; John C Butt, Halifax, Nova Scotia; Donald Cockcroft, Saskatoon, Saskatchewan; Graham Dowling, Edmonton, Alberta; Francis HY Green, Calgary, Alberta; Patrick A Hessel, Edmonton, Alberta; Arte Karkhanis, Winnipeg, Manitoba; Wayne Kepron, Winnipeg, Manitoba; Felix Li, Ottawa, Ontario; Yang Mao, Ottawa, Ontario; Peter Markesteyn, Winnipeg, Manitoba;

Dennis Michaelchuk, Edmonton, Alberta; Ian Mitchell, Calgary, Alberta; Monica Ruff, Calgary, Alberta; Lisa Semple, Calgary, Alberta; O Diane Stephenson, Regina, Saskatchewan; Suzanne Tough, Calgary, Alberta; Donald Wigle, Ottawa, Ontario

Correspondence: Dr Suzanne Tough, Division of Neonatology, Department of Pediatrics, Calgary Regional Health Authority C211C, 140329 Street NW, Calgary, Alberta T2N 2T9. Telephone 403-670-4938, fax 403-670-4892, e-mail suzanne.tough@crha-health.ab.ca 


\section{Facteurs influençant les consultations pour cause d'asthme au service des urgences}

HISTORIQUE : On peut habituellement maîtriser l'asthme par des mesures d'évitement des allergènes et/ou un traitement approprié. Une consultation aux urgences pour une exacerbation aiguë de d'asthme indique que ce dernier n'est pas maîtrisé. Les traitements administrés au service des urgences entraînent des dépenses de santé importantes et traduisent une diminution de la qualité de vie.

OBJECTIFS : Identifier les facteurs de risque associés à une consultation pour cause d'asthme au service des urgences.

MÉTHODES : Cette étude cas/témoins a comparé 299 personnes ( $76 \%$ des 390 cas contactés) qui se sont rendus à l'un des deux services des urgences, en Alberta, en 1992 et 1993 pour une exacerbation aiguë de leur asthme (cas), avec 212 témoins de la communauté non appariés, asthmatiques et localisés en composant un numéro de téléphone au hasard. On a demandé aux cas et aux témoins de remplir un questionnaire envoyé par la poste pour recueillir des données sur la gravité, les consultations chez un médecin et au service des urgences, l'utilisation des médicaments, les allergies et autres facteurs déclenchants, et la consommation de tabac. L'analyse des données comportait une analyse à deux variables des facteurs de risque et le développement d'un modèle à plusieurs variables en utilisant la régression logistique.

RÉSULTATS : Le taux de réponse était similaire pour les deux groupes étudiés. Les cas étaient plus jeunes que les témoins (risque relatif [RR] de 2,16 ; IC à $95 \%$; 1,34-3,48) et ont plus souvent rapporté leur asthme comme étant grave (RR de 4,25, IC à $95 \% ; 2,24-8,06$ ) ainsi que des symptômes nocturnes (fourchette du RR stratifié de 1,36 à 6,82). Les cas avaient consommé plus de soins de santé dans l'année précédente, avaient à un certain moment été hospitalisés à cause de leur asthme (RR de 1,62, IC à $95 \% ; 1,10-2,38)$ et prenaient plus de médicaments que les témoins.

CONCLUSIONS : Les médecins et les autres travailleurs de la santé devraient être sensibilisés aux facteurs de risque et aux interventions spécifiques chez les individus à risque élevé.

\begin{abstract}
$\mathrm{A}$ sthma is the most common chronic respiratory illness in North America and in recent years its prevalence has increased internationally (1-5). In the majority of cases, asthma can be controlled by allergen avoidance and/or appropriate medication; thus, a visit to an emergency department often represents a failure in the treatment or control process. Treatment of asthma in the emergency department involves significant cost to the health care system, and a disruption for the patient and caregivers (6).

To reduce the need for emergency department treatment of asthma, it is necessary to identify the characteristics of both the disease and the person that result in an emergency department visit. This study was undertaken to describe risk factors associated with an exacerbation of asthma serious enough to warrant an emergency department visit. It is understood that patients with asthma who visit an emergency department for treatment exhibit a range of illness at presentation and that many would not necessarily be classified as 'emergent'. The objective of the study was to identify risk factors for treatment of asthma in the emergency department by comparing patients seen in the emergency department (cases) with a random sample of people with asthma from the general population (controls). The goal of the study was to provide information that could be used to design programs aimed at improving quality of life for people with asthma and to identify high risk individuals who would benefit from these interventions.
\end{abstract}

\section{PATIENTS AND METHODS}

An unmatched case-control study was implemented from June 1992 to May 1993 in the cities of Edmonton and Lethbridge, Alberta. Cases were those persons aged five to 50 years seen for asthma in the emergency department at the University of Alberta Hospital in Edmonton or the Lethbridge Regional Hospital. The lower age limit was chosen to ensure that a reliable diagnosis of asthma could have been made. The upper limit was chosen to reduce the likelihood that chronic obstructive pulmonary disease was either a comorbidity or a true underlying condition (ie, minimizing misdiagnosis). To be eligible as a case, patients were required to have sought treatment for asthma and to have had a discharge diagnosis of asthma from the emergency department. Cases were contacted by phone within five days of their emergency department visit and invited to participate in the study by completing a self-administered, mailed questionnaire. Follow-up by phone was undertaken to a maximum of nine times, or until the participant declined participation; mail reminders and additional questionnaires were provided to those who had misplaced the original questionnaire. Of the 390 potential cases, completed questionnaires were obtained from 297 (76.1\%). The response rate for those in the Edmonton case group was 122 of 162 (75.3\%), which was similar to the response rate for patients from the Lethbridge hospital (175 of 228, 76.8\%).

Controls between the ages of five and 50 years were identified through random digit dialling according to a described procedure (6). From the 6425 random phone numbers, 275 people with asthma were identified; of these people, 212 (77.1\%) completed the questionnaire. Numbers for random digit dialing were obtained through the Population Research Laboratory (PRL) at the University of Alberta. The PRL maintains a listing of all assigned five-digit prefixes for Alberta (ie, the first five digits of the seven digit telephone number). The last two digits were then added randomly to the randomly generated prefixes. When sufficient numbers of controls had been identified, the remaining open lists of random numbers were exhausted, and recruitment was halted. Each number was dialed a minimum of nine times on different days at different times before it was considered exhausted. If an individual who had ever had a doctor diagnosis of asthma between the ages of five and 50 years lived in a home that was contacted, that individual was asked to partici- 
pate in the study by completing same questionnaire as cases. If more than one eligible person with asthma lived in the home, the individual with the birthday closest to the phone recruitment date was invited to participate. Only one participant/household was permitted. The questionnaire was mailed out, and followed-up by letter and telephone reminders. Of 6425 phone numbers completed, 275 asthmatics were recruited (4.3\% of telephone numbers). The response rates for controls were similar in Edmonton (161 of 208, 77.4\%) and Lethbridge (51 of $67,76.1 \%$ ).

The study was given ethical approval by the University of Alberta, the University of Alberta Hospital, and the Lethbridge Regional Hospital. All participants were notified that the information gathered was confidential and would not impact the type or quality of care. Parents were asked to complete questionnaires for participants aged five to 16 years. A copy of the study information sheet and the consent form was located at the front of the questionnaire.

The questionnaire was drafted by a group of physicians, epidemiologists and asthma experts, and took between 45 and 75 mins to complete. The questionnaire was pretested in a pilot study of 35 patients with asthma at two hospitals. The pretest results were used to resolve unclear wording.

The questionnaire (which can be obtained from the authors or the editor of the Canadian Respiratory Journal) contained 25 items. Information on the following topics was obtained.

- Overall asthma severity (severe - seriously interferes with normal lifestyle; moderate - occasionally interferes with normal lifestyle; mild - interferes infrequently with normal lifestyle); frequency of symptoms; need to visit doctor or emergency department; need to increase medications in the past 12 months; frequency of waking in the morning with symptoms; need for medications at night; and presence of cough and phlegm

- Use of medications in the previous month and 12 months (divided into beta-agonists; ipratropium; oral theophylline; inhaled steriods; inhaled cromoglycate; oral ketotifan fumerate; allergy shots; herbal remedies and naturopathic remedies); delay in filling prescriptions because of cost in the previous 12 months; and use of a peak flow meter and a written action plan.

- Allergies and triggers (pollens, molds, house dust and other dusts; cold and influenza; physical activity, stress, excitement, depression, animals, foods, drugs, cigarette smoke, wood smoke, burning field stubble, perfumes and fumes, cold air, and weather changes); and action taken (nothing; take medication with symptoms; take medication before exposure; avoid trigger)

- Health professionals prescribing treatments; family doctors seen in previous 12 months and previous two weeks; and specialist seen in previous 12 months and two weeks

- Hospitization ever; resuscitation ever
TABLE 1

Description of study population

\begin{tabular}{|c|c|c|c|c|}
\hline & $\begin{array}{l}\text { Cases } \\
\mathrm{n}(\%)\end{array}$ & $\begin{array}{c}\text { Controls } \\
\text { n (\%) }\end{array}$ & OR & $95 \% \mathrm{Cl}$ \\
\hline \multicolumn{5}{|l|}{ Sex } \\
\hline Male & $146(49.2)$ & $105(49.5)$ & 0.98 & $0.69-1.40$ \\
\hline Female & $151(50.8)$ & $107(50.5)$ & & \\
\hline \multicolumn{5}{|l|}{ Age group } \\
\hline 5 to 14 years & $122(41.4)$ & 65 (31.0) & 2.16 & $1.34-3.48$ \\
\hline 15 to 29 years & $120(40.7)$ & $84(40.0)$ & 1.64 & $1.04-2.61$ \\
\hline $\begin{array}{l}30 \text { years and } \\
\text { over }\end{array}$ & $53(18.0)$ & $61(29.0)$ & 1.00 & \\
\hline
\end{tabular}

- Smoking history including the depth of inhalation for cigarette, pipes and cigars

- Exposure to pets (cats, dogs, rabbits, gerbils/hamsters/guinea pigs) including current exposure, presence in bedroom, age of first exposure and whether symptoms provoked by exposure

Data analysis: Questionnaires were reviewed manually for consistency and appropriate coding before data entry. All data were entered twice into the Statistical Package for the Social Sciences-Data Entry (SPSS, Chicago, Illinois) and discrepancies resolved (7). The data were edited, and checked for appropriate codes and outliers, and for normality of the distributions of continuous variables. Risk factors chosen for evaluation in bivariate and regression analysis were those based on the literature and the expertise of the investigators. Initial univariate and bivariate analyses examined case-control differences using odds ratios (OR) and comparisons of means. When there was a gradient in the data, the Mantel Haenszel test for linear trend was used. Logistic regression techniques were used to develop a multivariate model that would distinguish case from control. Logistic regression was preferred to discriminant function analysis because it requires fewer assumptions about the data, ie, multivariate normality of the independent variables and equal variances, and because it performs well even when the assumptions for discriminant function analysis are met. EPI INFO 6.0 (Centers for Disease Control and Prevention, Atlanta, Georgia) was used for determining the ORs and confidence intervals (Cornfield method) in the stratified analysis. The Statistical Package for the Social Sciences was used for crosstabs and logistic regression. The cases were compared with the controls for demographic variables, self-reported asthma severity, health care use, medication use and duration of disease. The most salient case-control differences were noted.

\section{RESULTS}

There were no sex differences between the groups; about $51.0 \%$ of both groups were female (Table 1). The cases were slightly younger than the controls; $40.3 \%$ of the cases compared with $31.0 \%$ of controls was in the age five to 14 year age group (Table 1). Slightly over $90 \%$ of participants described themselves as Caucasian. 
TABLE 2

Comparison between cases and controls for characteristics of asthma

\begin{tabular}{|c|c|c|c|c|}
\hline & Cases n (\%) & Controls n (\%) & OR & $95 \% \mathrm{Cl}$ \\
\hline \multicolumn{5}{|l|}{ Self-reported severity } \\
\hline Mild & $88(29.9)$ & $110(52.1)$ & 1.00 & \\
\hline Moderate & $155(52.7)$ & $86(40.8)$ & 2.25 & $1.53-3.31$ \\
\hline Severe & $51(17.3)$ & $15(7.1)$ & 4.25 & $2.24-8.06$ \\
\hline \multicolumn{5}{|l|}{ Symptom frequency } \\
\hline None & $75(26.7)$ & $60(32.9)$ & 1.00 & \\
\hline With exercise only & $74(26.3)$ & $37(20.1)$ & 1.60 & $0.95-2.69$ \\
\hline One to two times/week & $63(22.4)$ & $47(25.5)$ & 1.07 & $0.65-1.78$ \\
\hline Three to four times/week & $30(10.7)$ & $20(10.9)$ & 1.20 & $0.62-2.32$ \\
\hline Five or more times/week & $39(13.9)$ & $20(10.9)$ & 1.56 & $0.83-2.95$ \\
\hline \multicolumn{5}{|c|}{ Night symptoms in past two weeks } \\
\hline None & $131(44.4)$ & $149(71.0)$ & 1.00 & \\
\hline $1-3$ & $106(35.9)$ & $38(18.1)$ & 3.17 & $2.05-4.92$ \\
\hline $4-8$ & $28(9.5)$ & $14(6.7)$ & 2.27 & $1.15-4.50$ \\
\hline $9-13$ & $6(2.0)$ & $5(2.4)$ & 1.36 & $0.41-4.58$ \\
\hline Every night & $24(8.1)$ & $4(1.9)$ & 6.82 & $2.31-20.18$ \\
\hline \multicolumn{5}{|c|}{ Often feel you have mucus to be coughed out } \\
\hline Yes & $174(63.3)$ & $116(63.4)$ & 1.0 & $0.68-1.47$ \\
\hline \multicolumn{5}{|c|}{ Have you ever had a life-threatening allergic reaction } \\
\hline Yes & $65(22.0)$ & $46(21.9)$ & 1.0 & $0.65-1.54$ \\
\hline
\end{tabular}

OR Odds ratio

TABLE 3

Comparison of health care use for cases and controls

\begin{tabular}{lcccc}
\hline & $\begin{array}{c}\text { Cases } \\
\mathbf{n ~ ( \% )}\end{array}$ & $\begin{array}{c}\text { Controls } \\
\mathbf{n ~ ( \% )}\end{array}$ & OR & Cl \\
\hline $\begin{array}{l}\text { Ever admitted for } \\
\text { asthma }\end{array}$ & $113(38.4)$ & $57(27.8)$ & 1.62 & $1.10-2.38$ \\
$\begin{array}{l}\text { Emergency department } \\
\text { visits in last }\end{array}$ & $152(51.4)$ & $32(15.1)$ & 5.94 & $3.83-9.22$ \\
$\quad 12$ months $^{*} \dagger$ & & & & \\
Family doctor visits $^{\dagger}$ & $227(76.9)$ & $113(54.3)$ & 2.80 & $1.91-4.12$ \\
$\begin{array}{l}\text { Unscheduled visit to the } \\
\text { doctor }\end{array}$ & $251(84.8)$ & $90(42.5)$ & 7.56 & $4.98-11.49$ \\
Increased medication $^{\dagger}$ & $196(66.2)$ & $84(40.0)$ & 2.94 & $2.04-4.24$ \\
$\begin{array}{l}\text { Ever had } \\
\text { cardiopulmonary } \\
\text { resuscitation or }\end{array}$ & $20(6.8)$ & $3(1.5)$ & 4.90 & $1.44-16.72$ \\
$\quad$ intubation & & & & \\
\hline
\end{tabular}

${ }^{*}$ Excluding index visit; ${ }^{\dagger}$ For asthma in the previous 12 months. OR Odds ratio

Self-reported severity was greater among cases than controls (Table 2). Seventy per cent of cases classified themselves as having moderate (interfering occasionally with normal lifestyle) or severe (seriously interfering with normal lifestyle) asthma compared with $47.9 \%$ of controls. However, frequency of usual asthma symptoms did not differ between the groups. Cases reported sleep disturbances during the previous two weeks significantly more often than controls, about two-thirds of each group reported a history of mucus in the chest, and approximately $22 \%$ of both groups reported a life-threatening allergic reaction.

When self-reported severity and nocturnal symptoms were entered into a stepwise logistic regression model, both remained significant, with an OR of 1.82 (95\% CI 0.75 to
2.45) for severity and an OR of 2.45 (95\% CI 1.64 to 3.65) for nocturnal symptoms.

Cases were significantly more likely to have a history of hospital admission for asthma, to have used the emergency department in the past 12 months (excluding the recruitment index visit), to have seen their family doctor for asthma in the previous 12 months, to have made an unscheduled visit to the doctor for asthma in the past 12 months and to have increased their use of medication in the previous 12 months (Table 3). A history of cardiopulmonary resuscitation or intubation was reported by a minority of participants in both groups but was significantly more common among cases. When these variables were entered into a stepwise logistic regression analysis, only use of the emergency department (OR 3.74, 95\% CI 2.30 to 6.07), unscheduled visits to the doctor (OR 5.92, 95\% CI 3.72 to 9.30) and cardiopulmonary resuscitation or intubation (OR 4.03, 95\% CI 1.0 to 16.32 ) remained significant.

The proportion of cases and controls receiving specialist care was $29.5 \%$ and $19.1 \%$, respectively. Cases were significantly more likely to be under the care of a specialist (OR $1.71,95 \%$ CI 1.10 to 2.68 ) and had a respiratory doctor prescribe their medication (OR 1.74, 95\% CI 1.02 to 2.97). Regarding management, although cases were significantly more likely to use a peak flow meter at least once per week (OR $2.50,95 \%$ CI 1.45 to 4.34 ), they were no more likely to use an action plan, which described what to do as asthma control deteriorated (OR 1.52, 95\% CI 0.86 to 2.72).

All asthma medications were used more often by cases compared with controls (Table 4). Of note, steroid tablets had been used occasionally or daily by $44.1 \%$ of cases compared with $11.2 \%$ of controls. Inhaled steroids were used by $65 \%$ of all cases; $34.7 \%$ of all cases used them occasionally 
TABLE 4

A comparison of medication use for cases and controls

\begin{tabular}{lcccc}
\hline & $\begin{array}{c}\text { Cases } \\
\mathbf{n}(\%)\end{array}$ & $\begin{array}{c}\text { Controls } \\
\mathbf{n}(\%)\end{array}$ & OR & $\mathbf{9 5 \%} \mathbf{~ C l}$ \\
\hline Beta-agonist & & & & \\
$\quad$ None & $20(7.0)$ & $46(22.7)$ & 1.0 & \\
Occasionally & $158(55.4)$ & $116(57.1)$ & 3.13 & $1.76-5.58$ \\
$\quad$ Every day & $107(37.5)$ & $41(20.2)$ & 6.00 & $3.18-11.34$ \\
Bronchodilator + theophylline & & & \\
$\quad$ None & $202(77.1)$ & $188(92.2)$ & 1.0 & \\
Occasionally & $28(10.7)$ & $7(3.4)$ & 3.72 & $1.59-8.73$ \\
Every day & $32(12.2)$ & $9(4.4)$ & 3.31 & $1.54-7.12$ \\
Inhaled steroids & & & & \\
$\quad$ None & $96(35.0)$ & $131(64.5)$ & 1.0 & \\
$\quad$ Occasionally & $95(34.7)$ & $42(20.7)$ & 3.09 & $1.97-4.83$ \\
$\quad$ Every day & $83(30.3)$ & $30(14.8)$ & 3.78 & $2.30-6.19$ \\
Steroid tablets & & & & \\
$\quad$ None & $150(56.0)$ & $182(88.8)$ & 1.0 & \\
$\quad$ Occasionally & $106(39.6)$ & $22(10.7)$ & 5.85 & $3.52-9.71$ \\
Every day & $12(4.5)$ & $1(0.5)$ & 14.56 & $1.87-113.26$ \\
\hline
\end{tabular}

OR Odds ratio

TABLE 5

A comparison of triggering factors and environmental exposures between emergency department cases and RDD controls

\begin{tabular}{lrrrc}
\hline & $\begin{array}{c}\text { Cases } \\
\mathbf{n}(\%)\end{array}$ & $\begin{array}{c}\text { Controls } \\
\mathbf{n}(\%)\end{array}$ & OR & $\mathbf{9 5 \% ~ C l}$ \\
\hline House dust & $160(55.6)$ & $133(62.7)$ & 0.74 & $0.51-1.07$ \\
Weather & $166(57.4)$ & $98(46.4)$ & 1.56 & $1.09-2.22$ \\
$\quad$ changes & & & & \\
Cigarette smoke & $196(68.1)$ & $149(70.3)$ & 0.90 & $0.61-1.32$ \\
Stress & $112(39.2)$ & $66(31.3)$ & 1.41 & $0.97-2.06$ \\
Depression & $37(12.9)$ & $25(11.8)$ & 1.11 & $0.65-1.91$ \\
Excitement & $89(30.9)$ & $58(27.4)$ & 1.19 & $0.80-1.76$ \\
Animals & $180(62.7)$ & $127(59.9)$ & 1.13 & $0.78-1.62$ \\
Colds and & $234(81.0)$ & $144(67.9)$ & 2.00 & $1.33-3.03$ \\
$\quad$ influenza & & & & \\
Drugs & $41(14.3)$ & $16(7.6)$ & 2.03 & $1.11-3.73$ \\
Physical activity & $223(77.2)$ & $148(69.8)$ & 1.46 & $0.98-2.18$ \\
Wood smoke & $104(36.2)$ & $60(28.8)$ & 1.40 & $0.95-2.06$ \\
Foods & $69(24.0)$ & $46(21.7)$ & 1.14 & $0.74-1.74$ \\
Perfumes and & $100(35.0)$ & $69(32.5)$ & 1.11 & $0.76-1.62$ \\
$\quad$ fumes & & & & \\
Molds & $114(39.7)$ & $90(43.1)$ & 0.87 & $0.61-1.25$ \\
Pollens & $180(62.5)$ & $132(62.9)$ & 0.98 & $0.68-1.40$ \\
\hline
\end{tabular}

OR Odds ratio

and $30.3 \%$ of all cases used them daily (65\%). When all of the variables for medication use were entered into a multivariate model, only the use of beta-agonist bronchodilators (OR 1.82, 95\% CI 1.13 to 2.92) and inhaled steroids (OR $1.86,95 \%$ CI 1.11 to 3.13 ) remained statistically significant. Odds ratios were calculated based on ever versus never use in the past 12 months.

Although information on health care insurance for medication was not obtained, $23.3 \%$ of cases and $22.0 \%$ of controls had failed to fill prescriptions due to cost (OR 1.07, $95 \%$ CI 0.69 to 1.68$)$.
TABLE 6

Comparison between emergency department and RDD (spell out) patients with asthma for smoking among those age 15 and over

\begin{tabular}{lrrrr}
\hline & $\begin{array}{c}\text { Cases } \\
\mathbf{n}(\%)\end{array}$ & $\begin{array}{c}\text { Controls } \\
\mathbf{n}(\%)\end{array}$ & OR & $\mathbf{9 5 \% ~ C l}$ \\
\hline Severe & & & & \\
$\quad$ Current & $4(11.1)$ & $3(37.5)$ & 1.00 & \\
Ex-smoker & $5(13.9)$ & $3(37.5)$ & 1.25 & $0.16-9.92$ \\
$\quad$ Nonsmoker & $27(75.0)$ & $2(25.0)$ & 10.13 & $1.27-80.61$ \\
Moderate & & & & \\
$\quad$ Current & $18(20.7)$ & $13(25.0)$ & 1.00 & \\
Ex-smoker & $11(12.6)$ & $16(30.8)$ & 0.50 & $0.17-1.42$ \\
$\quad$ Nonsmoker & $58(66.7)$ & $23(44.2)$ & 1.82 & $0.77-4.31$ \\
Mild & & & & \\
$\quad$ Current & $12(25.0)$ & $21(25.0)$ & 1.00 & \\
$\quad$ Ex-smoker & $8(16.7)$ & $17(20.2)$ & 0.82 & $0.27-2.47$ \\
$\quad$ Nonsmoker & $28(58.3)$ & $46(54.8)$ & 1.07 & $0.45-2.49$ \\
\hline OR Odds ratio & & & &
\end{tabular}

TABLE 7

Final logistic regression model

\begin{tabular}{lcccc}
\hline Variable & $\begin{array}{c}\text { Odds } \\
\text { ratio }\end{array}$ & $\mathbf{9 5 \%} \mathbf{C l}$ & SE & P \\
\hline $\begin{array}{l}\text { Use of emergency } \\
\text { department }\end{array}$ & 3.03 & $1.82-5.04$ & 0.26 & 0.0000 \\
$\begin{array}{l}\text { Unscheduled visits to } \\
\text { doctor }\end{array}$ & 6.01 & $3.68-9.81$ & 0.25 & 0.0000 \\
$\begin{array}{l}\text { Night symptoms } \\
\text { Variables excluded }\end{array}$ & 2.44 & $1.52-3.91$ & 0.24 & 0.0002 \\
$\quad$ Triggered by cold air & & & & \\
$\quad \begin{array}{l}\text { Cardiopulmonary } \\
\text { resuscitation }\end{array}$ & & & & \\
$\quad \begin{array}{l}\text { Use of beta-agonists } \\
\text { Use of inhaled } \\
\text { steroids }\end{array}$ & & & & \\
$\quad$ Severity & & & & \\
\hline SE Standard error & & & &
\end{tabular}

From the list of potential asthma triggers included on the questionnaire, cases were significantly more likely to choose colds and influenza, drugs, and weather changes (Table 5). None of the triggers were reported significantly more often by controls. When the three statistically significant variables were entered into a stepwise logistic regression model, only the "colds and "flu" variable remained statistically significant (OR 1.98, 95\% CI 1.31 to 2.99); the other two were marginally nonsignificant.

The relationship among smoking, asthma severity and emergency department visits was examined for those age 15 years and over in a stratified analysis (Table 6). Those with severe asthma who were seen in the emergency department were significantly more likely to be nonsmokers than the random digital dialling participants, although, the numbers are small. Furthermore, $66.0 \%$ of those in the emergency department group reported never having smoked compared with $49.3 \%$ of those in the RDD group (never versus ever, OR $2.00,95 \%$ CI 1.24 to 3.24 ). 
Those in the emergency department group were no more likely to keep pets than RDD controls, regardless of disease severity (OR $1.02,95 \%$ CI 0.71 to 1.48 ), and $52.7 \%$ of cases and $52.1 \%$ of controls currently had an indoor pet. Futhermore, $62.6 \%$ of those who had an indoor pet reported that their asthma was triggered by animals.

To complete the analysis, all variables found to be significant within their category (ie, health care use, asthma medication) were entered into a stepwise regression. Previous use of the emergency department, unscheduled visits to the doctor and nocturnal symptoms remained significantly associated with case-control status (Table 7). The variables excluded at this step included triggered by colds or influenza, history of cardiopulmonary resuscitation, use of beta-agonists, use of inhaled steroids and self-reported severity.

\section{DISCUSSION}

The study relied on self-reported data collected using a questionnaire; reliability and validity of self-reported data obtained by questionnaire has been investigated (9-11), and self-report of sensitive issues may not be reliable (11). However, when the information is not used for assessing individual treatment and does not have any impact on clinical care, as in the present study, self-reporting provides generally reliable and valid data (9). There was some concern that the cases who had just experienced an emergency department visit for asthma might exhibit better (or biased) recall than controls. The questionnaire was designed to provide objective information, and it was felt that most questions were straightforward. Nonetheless, potential differences in recall between cases and controls should be considered.

The diagnosis of asthma among the controls was dependent on the individual having received a doctor's diagnosis of asthma. The diagnosis of asthma may vary between different doctors, and, in some instances, doctors may choose not to inform some patients with milder asthma of their diagnosis. If this were the case, we would expect the controls to have slightly more severe disease than the global population of those with asthma, serving to bias the risk estimates towards the null. Furthermore, we noted that some of controls had an emergency room visit for asthma in the preceding 12 months, which would have biased the risk estimates towards the null; however, we noted significant differences between groups.

The present study has some advantages over previous research, particularly in the size of the sample and the selection of a control group for comparison. Much of the existing data in this area stems from clinical or descriptive studies. Some clinical studies have been limited by small sample sizes or very select homogeneous patient populations $(12,13)$. Although a great deal of attention has been focused on describing high risk asthmatics, specifically those admitted to hospital and those with difficulty controlling their disease, less attention has been paid to determining the characteristics that distinguish these individuals from others with asthma (14-16). The comparison of a variety of factors between groups of asthmatics provided an opportunity to identify characteristics that could potentially be modified so that the need for emergency department treatment among those at risk could be reduced. Because the major objective of this study was to identify asthmatics at risk of an emergency department visit, unmatched controls were preferable to matched. Matching would have limited our ability to describe the demographic profile of the individual, including age, sex and asthma severity.

The finding that cases were significantly younger than controls may suggest parents or caregivers take their children to the emergency department more readily when asthma control deteriorates than an adult would seek assistance for his or her own asthma. Parents have cited their inability to relieve their child's symptoms as a major component of the burden of disease (17). Younger people may also have less experience in dealing with asthma.

Asthma was reported to be significantly more severe for cases compared with controls. Although the classification of the severity of asthma is difficult because of the chronic and episodic nature of the disease, self-reported asthma severity was found in this study to correlate highly with other markers of severity. This is in agreement with other studies indicating that objective markers of asthma severity generally correlate with self-report $(18,19)$. Interestingly, although self-reported severity could be considered a factor that would be expected to influence emergency admissions, we did not find it to be significant in the final model. It should be noted, however, that the recent emergency department visit of the cases might have affected their self-assessment of asthma severity.

It was noted that those seen in the emergency department were significantly more likely to be under the care of a respiratory specialist and to use a peak flow meter; however, specialist care was still received only by $24 \%$ of cases, which may suggest that specialized care is underutilized.

Medication was used more often by cases than controls but, despite the substantial history of poorly controlled asthma among cases, only 30\% were taking an inhaled corticosteroid on a daily basis. It is unclear whether the heavy use of beta-agonist medication reflects greater severity of the disease, poor control, or whether medication use can be considered etiologically important (20).

Given the large number of triggers for asthma that were compared between cases and controls, the opportunity may have existed for observing a statistically significant difference due to chance. Although, the three significant findings should be interpreted with caution, the findings may be useful for hypothesis generation. As well, only the colds and influenza variable remained significant in the multivariate analysis, perhaps suggesting that triggers for cases and controls are very similar; however, the degree of response may differ.

The finding that over half of all cases and controls currently lived with a pet and that $62.6 \%$ of those who kept a pet reported that animals trigger their asthma suggests that the relationship between asthma and pets is complex. Further research into the potentially cumulative effects of exposure to animal dander and its relationship to asthma is important. As 
well, education about the potential for animal dander to trigger asthma is warranted.

Current data from Statistics Canada suggests that smoking prevalence among those over age 15 years is $29.0 \%$ (21). Our findings that about $25.0 \%$ of those with moderate and mild asthma were current smokers suggest that overall asthmatics smoke as much as nonasthmatics. However, those with severe asthma do smoke less, possibly reflecting the impact of the disease on their ability to smoke.

The three variables most predictive of case-control status were nocturnal symptoms, unscheduled visits to the doctor and prior use of the emergency department. Recent nocturnal symptoms were more commonly reported by cases than controls, perhaps suggesting that control of asthma was less adequate in cases than controls. Furthermore, chronic nocturnal symptoms may be a marker of instability that predicts the likelihood of ultimately needing emergency department care. An alternative explanation is that patients with nocturnal symptoms may have more severe disease. Nocturnal asthma has been linked to gastric aspiration $(22,23)$. Furthermore, recent biopsy studies have shown an influx of inflammatory cells (eosinophils) into the airways at night in those with nocturnal symptoms but not in those with asthma who do not

\section{REFERENCES}

1. Evans R III, Mullally DI, Wilson RW, et al. National trends in the morbidity and mortality of asthma in the US. Chest 1987;91(Suppl 6):65S-74S.

2. Sears MR, Rea HH, Beaglehole R, et al. Asthma mortality in New Zealand; a two year national study. NZ Med J 1985;98:271-5.

3. Sly RM. Mortality from asthma. 1979-84. J Allergy Clin Immunol 1988;82:705-17.

4. Williams MH Jr. Increasing severity of asthma from 1960-87. N Engl J Med 1989;320:1015-6.

5. Wigle DT. Highlights of the national workshop on asthma, Ottawa, May 1988. Can Med Assoc J 1989;140:671-3.

6. Potthoff RF. Telephone sampling in epidemiology research; to reap the benefits, avoid the pitfalls. Am J Epidemiol 1994;139:967-78.

9. Rand CS, Wise RA. Measuring adherence to asthma medication regimes. Am J Respir Crit Care Med 1994;149(Suppl 2 Pt 2): S69-76.

10. Campbell DA, McLennan G, Coates JR, et al. Near fatal asthma attacks: the reliability of descriptive information collected from close acquaintances. Thorax 1993;48:1099-104.

11. Nelson LM, Longstreth WT Jr, Koepsell TD, Checkoway H, van Belle G. Completeness and accuracy of interview data from proxy respondents; demographic, medical and life-style factors. Epidemiology 1994;5:204-17.

12. Lowenthal M, Patterson R, Greenberger PA, Grammer LC. The application of an asthma severity index in patients with potentially fatal asthma. Chest 1993;104:1329-31.

13. Sly PD, Cahill P, Willet K, Burton P. Accuracy of mini peak flow meters in indicating changes in lung function in children with asthma. BMJ 1994;308:572-4.

14. Bailey WC, Richards JM Jr, Manzella BA, Brooks CM, Windsor RA, Soong SJ. Characteristics and correlates of asthma in a university clinic population. Chest 1990;98:821-8.

15. Dales RE, Schweitzer I, Kerr P, Gougeon L, Rivington R, Draper J. have nocturnal symptoms (24-26). The importance of nocturnal symptoms as a determinant of an emergency department visit in the light of data suggesting that nocturnal asthma may have unique features raises questions regarding therapeutic approaches.

All aspects of health care use that were evaluated were significantly more common among cases than controls. Repeated use of the emergency department for asthma (the most strongly predictive aspect) often reflects an inability to maintain control of the disease. Over half (51.4\%) of the cases had more than one emergency department visit in the previous 12 months compared with $15.1 \%$ of controls. Deterioration in control was evidenced by increases in the amounts and types of medication used, and unscheduled visits to the family doctor or specialist. Loss of control in this population did not appear to be related to undertreatment or inability to access the health care system.

ACKNOWLEDGEMENTS: Supported by the Laboratory Centre for Disease Control, Alberta Heritage Foundation for Medical Research and the Alberta Lung Association. The authors acknowledge the assistance of Dr Duncan Sanders, Dr Steven Newman, Dr Howard Aronson and Dennis Michaelchuk.

Risk factors for recurrent emergency department visits for asthma. Thorax 1995;50:520-4.

16. Molfino NA, Nannini LJ, Martelli AN, Slutsky AS. Respiratory arrest in near-fatal asthma. N Engl J Med 1991;324:285-8.

17. Townsend M, Feeny DM, Guyatt GH, Furlong WJ, Seip AE, Dolovich J. Evaluation of the burden of illness for pediatric asthmatic patients and their parents. Ann Allergy 1991;67:403-8.

18. Janson-Bjerklie S, Ferketich S, Benner P, Becker G. Clinical markers of asthma severity and risk: importance of subjective as well as objective factors. Heart Lung 1992;21:265-72.

19. O'Conner GT, Weiss ST. Clinical and symptom measures. Am J Respir Crit Care Med 1994;149(Suppl 2 Pt 2):S21-8.

20. Spitzer WO, Suissa S, Ernst P, Horwitz RI, et al. The use of beta-agonists and the risk of death and near death from asthma. N Engl J Med 1992;326:501-6.

21. Health Canada. National Population Health Survey Highlights No 1: Smoking Behaviour of Canadians (cycle 2 1996/1997). Ottawa: Health Canada, 1999.

22. Barnes PJ. Inflammatory mechanisms and nocturnal asthma. Am J Med 1988;85(Suppl 1B):64-70.

23. Busse WW. Pathogenesis and pathophysiology of nocturnal asthma. Am J Med 1988;85S:24-9.

24. Postma DS, Oosterhoff Y, Van Aalderen WMC, Kauffman HF, Wempe B, Koeter GH. Inflammation in nocturnal asthma? Am J Respir Crit Care Med 1994;150(Suppl 5 Pt 2):S83-6.

25. Martin RJ, Cicutto LC, Smith HR, Ballard RD, Szefler SJ. Airways inflammation in nocturnal asthma. Am Rev Respir Dis 1991;143:351-7.

26. Oosterhoff Y, Kauffman HF, Rutgers B, Zijlstra FJ, Koeter GH, Postma DS. Inflammatory cell number and mediators in bronchoalveolar lavage fluid and peripheral blood in subjects with asthma with increased nocturnal airways narrowing. J Allergy Clin Immunol 1995;96:219-29. 


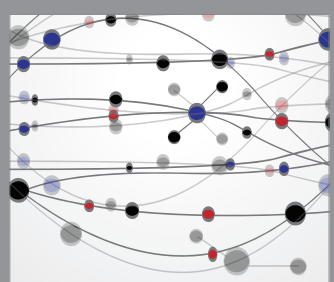

The Scientific World Journal
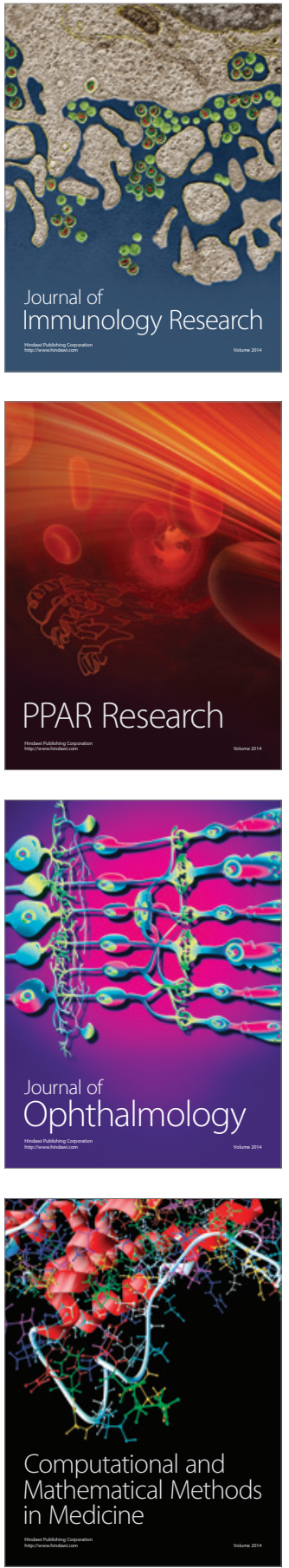

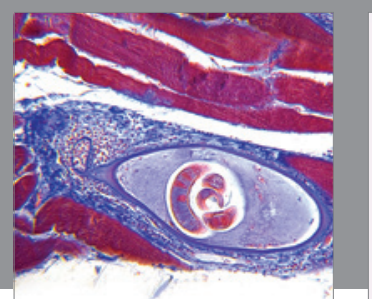

Gastroenterology Research and Practice

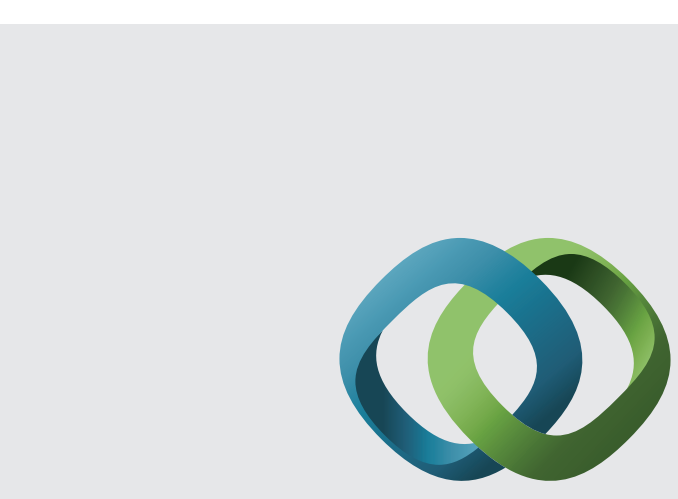

\section{Hindawi}

Submit your manuscripts at

http://www.hindawi.com
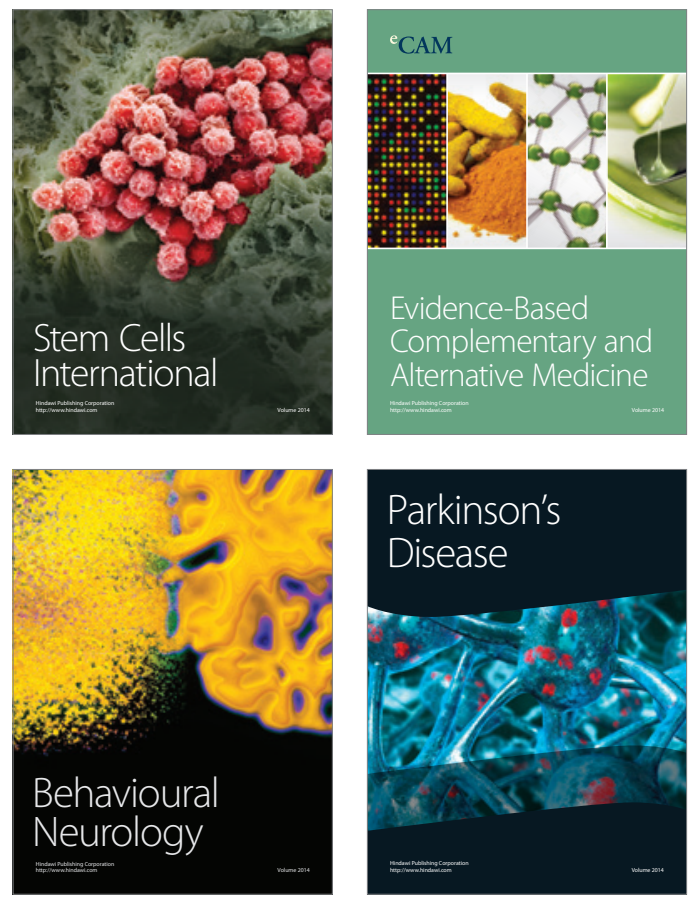
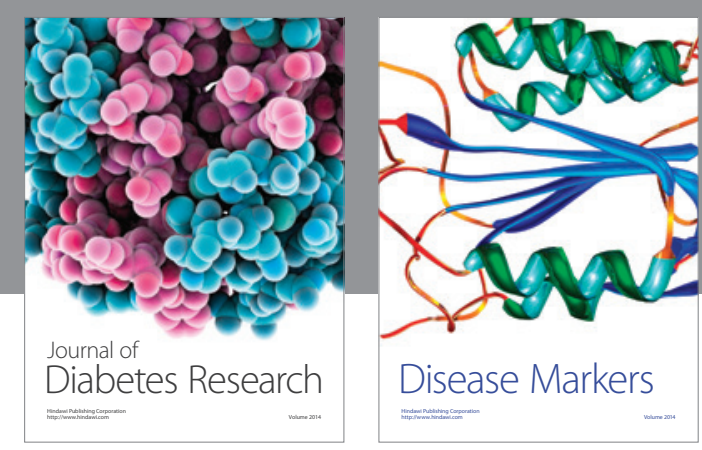

Disease Markers
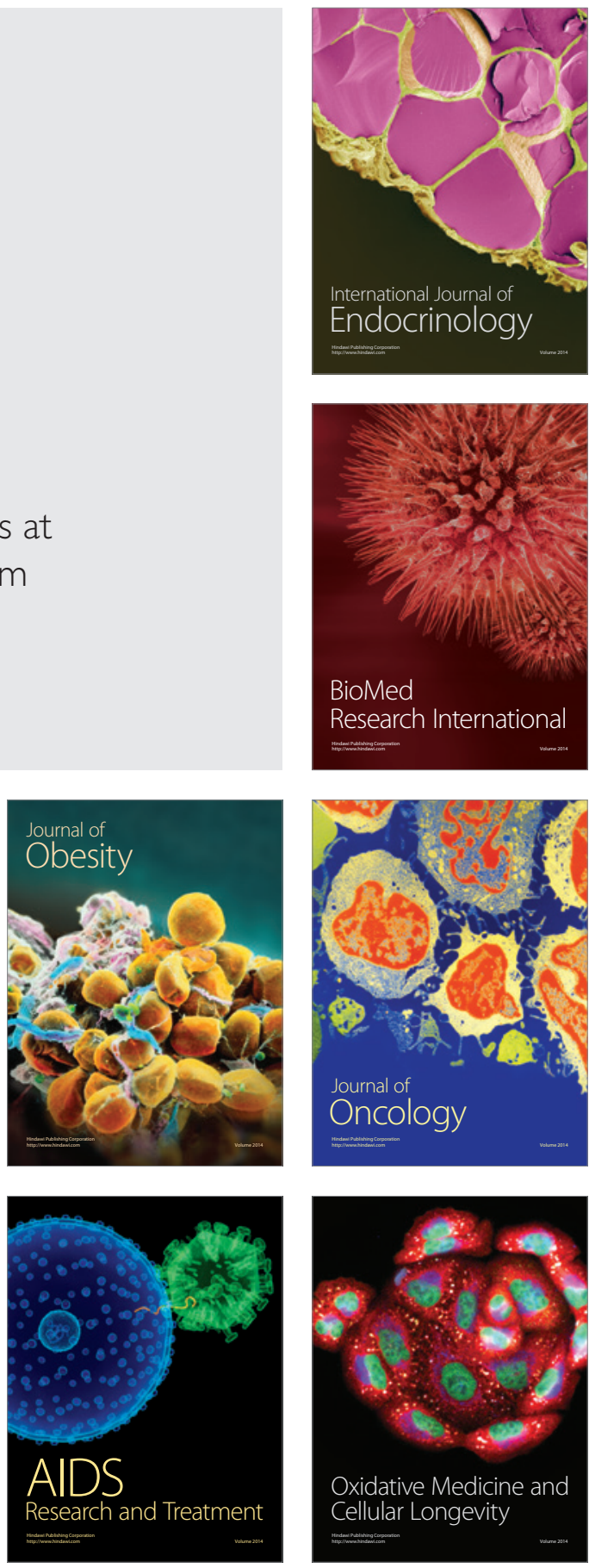